Poster Section

\title{
Plant substrate as a vehicle for trituration: a pilot study
}

\author{
Aildo Ferreira dos Santos Junior, Edmilson Roma de Oliveira, \\ Rodrigo Mariani Verginelli, Carlos Renato Zacharias \\ Univ Estadual Paulista - UNESP, Guaratinguetá, Brazil
}

\begin{abstract}
Motivation: Lactose and hydroalcoholic solutions are not the proper substances to study the High Dilution (HD) effects using plant models. Plant substrate can not be considered an inert vehicle, but it is not harmful to plants. Aim: In this pilot study we verify the possibility to use plant substrate as a trituration vehicle to prepare substances to be used in plants. Methods: We used a partially dried commercial plant substrate ( $12 \%$ humidity) as the vehicle to prepare a set of trituration, having $\mathrm{NaCl}$ as the initial active substance. Triturations were performed using a ball mill, with a mass dilution rate of 1:18 (set A) and 1:100 (set B), up to the $7^{\text {th }}$ trituration, that is, each set contained 8 groups: $A_{0}$ to $A_{7}$ and $B_{0}$ to $B_{7}$. For each group, the triturated substrate was mixed with a fresh one in a mass ratio of 1:1. After homogenization, 18 seeds of radish (Raphanus sativus) were sown in plastic trays $(31 \mathrm{ml}$ cell), for each group and kept in a green house exposed to natural thermal and light variations. After 4 weeks we determine the germination rate and number of mature cotyledon. Then 5 plants from each group were selected at random to determine the following parameters: averaged leaf area, length, fresh and dry mass and pigments amount (chlorophyll a and b, carotenes). Results: Groups $\mathrm{A}_{0}$ and $\mathrm{B}_{0}$ (higher saline concentration) showed those typical effects of saline
\end{abstract}

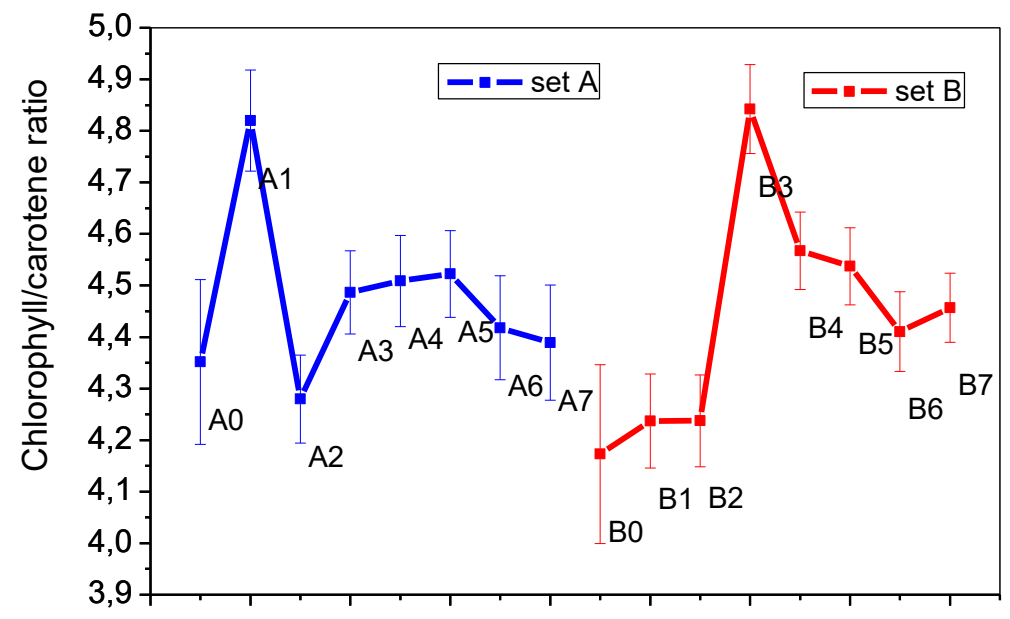

Figure 1: chlorophyll to carotene ratio $(\mathrm{CCr})$

stress: lower germination ratio, immature cotyledons, smaller and shorter leaves, higher water content and less pigments. All the others groups showed similar results, for all parameters, except pigments amount. The chlorophyll to carotene ratio (CCr) showed an unexpected but interesting behavior (figure 1).

Both sets showed an initial CCr growing (as expected due the saline ratio decrease), but followed by an unexpected decrement. Set B (the higher mass dilution rate, 1:100) showed a slower change, compared to set 
A. When we sort the results in order of saline amount we observe two peaks (figure 2), indicating that this behavior can not be explained by the saline stress.

Conclusions: Trituration using plant substrate as vehicle can be suitable to assess HD effects in plant models. In this pilot study we observed unusual results regarding to the expected saline stress due the saline concentration.

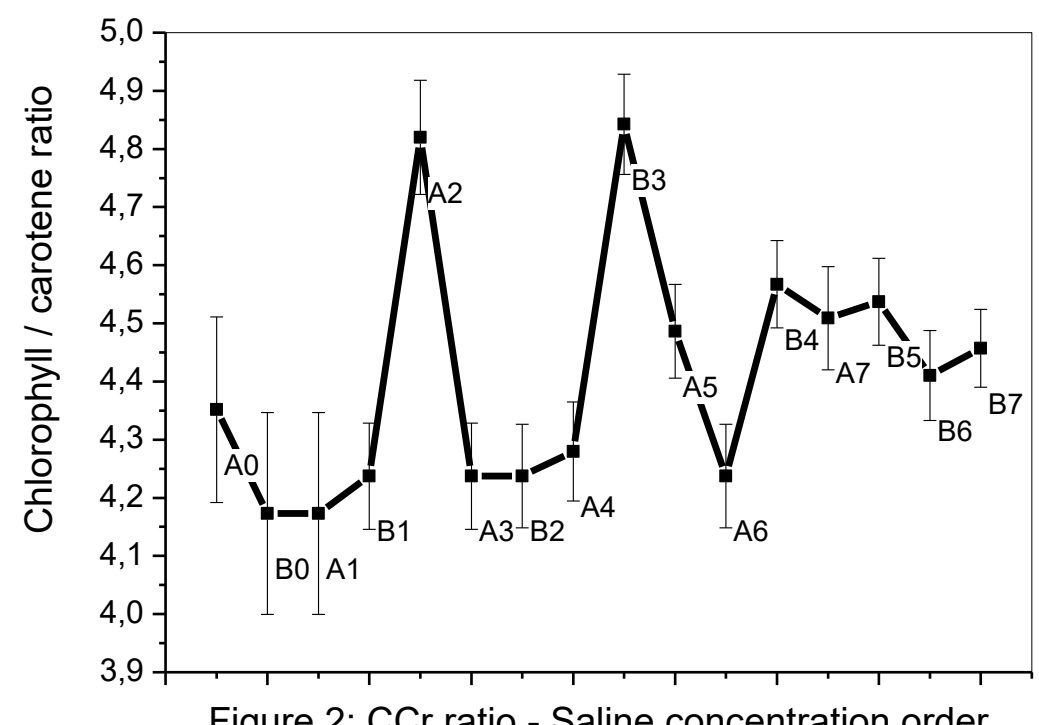

Figure 2: CCr ratio - Saline concentration order

\section{(c)) BY-NC-ND Licensed to GIRI}

Support: UNESP, FAPESP, CNPq

Conflict of interest: authors declare there is no conflict of interest

Received: 01 June 2012; Revised: 10 August 2012; Published: 30 September 2012.

Correspondence author: Carlos Renato Zacharias, zacha@feg.unesp.br, www.feg.unesp.br/ zacha

How to cite this article: dos Santos Junior AF, de Oliveira ER, Verginelli RM, Zacharias CR. Plant substrate as a vehicle for trituration: a pilot study. Int J High Dilution Res [online]. 2012 [cited YYYY Month dd]; 11(40):182-183. Proceedings of the XXVI GIRI Symposium; 2012 Sep 20-22; Florence (Italy). GIRI; 2012; Available from: http://www.feg.unesp.br/ ojs/index.php/ijhdr/article/view/558/597 